This version of the article has been accepted for publication, after peer review but is not the Version of Record and does not reflect post-acceptance improvements, or any corrections. The Version of Record is available online at: http://dx.doi.org/10.1007/s11625-021-01049-z. Use of this Accepted Version is subject to the publisher's Accepted Manuscript terms of use https://www.springernature.com/gp/openresearch/policies/accepted- manuscript-terms

\title{
A novel ecosystem (dis)service cascade model to navigate sustainability problems and its application in a changing agricultural landscape in Brazil
}

\section{Authors:}

Julien Blanco ${ }^{\mathrm{a},}$, Beatriz Bellón ${ }^{\mathrm{b}, \mathrm{c}}$, Liane Barthelemy ${ }^{\mathrm{d}}$, Baptiste Camus ${ }^{\mathrm{d}}$, Louise Jaffre ${ }^{\mathrm{d}}$, Anne-Sophie Masson $^{\mathrm{d}}$, Alix Masure ${ }^{\mathrm{d}}$, Fabio de Oliveira Roque ${ }^{\mathrm{e}, \mathrm{f}}$, Franco L. Souza ${ }^{\mathrm{e}}$, Pierre-Cyril Renaud ${ }^{\mathrm{b}}$

a SENS, IRD, CIRAD, Univ Paul Valery Montpellier 3, Univ Montpellier, Site St Charles, Route de Mende, 34199 Montpellier Cedex 5, France

b UMR CNRS 6554 LETG-Angers, UFR Sciences, Université d'Angers, 2 boulevard Lavoisier, 49045 Angers, France

${ }^{\mathrm{c}}$ Department of Environmental Science, Rhodes University, Makhanda, 6140, South Africa

${ }^{\mathrm{d}}$ UR ADI-Suds (Agrodéveloppement et innovation aux Suds), Istom, College of International Agro-

Development, 4 rue Joseph Lakanal, 49000 Angers, France

e Instituto de Biociências, Universidade Federal de Mato Grosso do Sul, Cidade Universitária, Caixa Postal 549, CEP 79070-900, Campo Grande, MS, Brazil

${ }^{\mathrm{f}}$ Centre for Tropical Environmental and Sustainability Science (TESS) and College of Science and Engineering, James Cook University, Cairns, QLD 4878, Australia

*Corresponding author:

Université Paul-Valéry, UMR SENS - St Charles, Route de Mende, 34199 Montpellier Cedex 5

Email address: julien.blanco@ird.fr - Phone: +33(0)6 87901110 


\begin{abstract}
The ecosystem service framework has been instrumental in navigating local to global sustainability issues. Yet as ecosystem services (ES) focus on nature's positive contributions to people, some have argued that 'ecosystem disservices' (EDS), or nature's negative contributions, should also be taken into account to better orient sustainability policies. However, joint ES and EDS assessments remain rare in sustainability research, partly because of the persisting conceptual ambiguity around the EDS concept. This study aimed to develop these joint assessments and test their relevance in addressing sustainability issues. To this end, we devised a novel cascade model that helps to define ES and EDS in a multi-level context that considers both as coproduced by ecosystems and people. In order to explore the potential and limitations of this model, we then applied it in a Brazilian landscape where reconciling agriculture and forest conservation is a critical sustainability challenge. Using the model in comprehensive interviews with farmers about their perceptions and management practices of forests, we found that they had an overall positive valuation of forests, but identified both positive and negative interactions between forests and farms at different organizational levels. The model also revealed a vicious circle between crop expansion, a resulting decrease in certain ES and an increase in certain EDS, which might exacerbate tensions between agriculture and forest conservation in the future. Additionally, the model allowed a window on the diverse preventive and regulating practices that the interviewed farmers have adopted to cope with increasing EDS without necessarily harming biodiversity. Based on this case study, this novel cascade model seems a promising conceptual tool to uncover the interactions between ES and EDS, opening new research and policy avenues to support sustainability.
\end{abstract}

\title{
Keywords
}

Cerrado; Conceptual framework; Coproduction of ecosystem services; Forest conservation; Nature's contributions to people; Socio-cultural valuation. 


\section{Introduction}

The ecosystem service (ES) concept has received considerable attention in recent decades from both the scientific and political spheres dealing with environmental issues. Initially, ES had an educative function (i.e. raising awareness of how humans depend on ecosystems), and progressively acquired a scientific function (i.e. improving the understanding of socio-ecological systems) as well as a decision-support function (Norgaard 2010; Ainscough et al. 2019). The concept's multi-faceted use means that ES have multiple, sometimes competing, meanings, which has resulted in a range of conceptual frameworks, perspectives, and debates (Fisher et al. 2009; Schröter et al. 2014; Barnaud and Antona 2014; Díaz et al. 2018). This lack of unified understanding can hinder the clarity of the ES concept, which is a key concern in certain research such as environmental accounting (Boyd and Banzhaf 2007; Potschin and Haines-Young 2011). Yet this ambiguity can also allow ES to play the role of a boundary object that facilitates dialogue between academic disciplines and stakeholders (Star and Griesemer 1989; Ainscough et al. 2019). As a consequence, ES definitions have constantly navigated between rigidity and flexibility with the dual aim of providing robust and comparable ES assessments across case studies (Fisher et al. 2009) while embracing different worldviews and perspectives (Díaz et al. 2018).

In terms of these objectives, one of the controversies around the ES concept has been its capacity (or incapacity) to take into account negative impacts on human well-being by ecosystem entities and processes (Lyytimäki and Sipilä 2009; Shackleton et al. 2016). Over a decade ago, the concern was raised that ecosystems should not only be considered as a source of services and benefits, but also as a source of 'disservices' and costs due to zoonotic diseases, crop raiding by wildlife, carnivore predation on humans and livestock, etc. (McCauley 2006; Dunn 2010). Since then, the 'ecosystem disservice' (EDS) concept has been discussed in many opinion papers (e.g. Lyytimäki and Sipilä 2009; Shapiro and Báldi 2014; Lyytimäki 2015), with repeated calls for joint ES-EDS assessments in order to better understand the complex links between ecosystems and human well-being with the aim of improving sustainability policies (Schaubroeck 2017; Blanco et al. 2020a).

Despite this, studies that account for both ES and EDS remain rare (Blanco et al. 2019a), which is partly due to a two-fold conceptual ambiguity around the EDS concept (Von Döhren and Haase 2015; Saunders 2020). First, there is no consensus on the delineation between EDS and the detriments they produce. Some effectively understand EDS as the subset of ecological functions that have actual or perceived negative impacts on human well-being (e.g. Lyytimäki and Sipilä 2009; Shackleton et al. 2016), while others use EDS to refer to the negative impacts and costs themselves, caused by ecological functions (e.g. Escobedo et al. 2011; Huang et al. 2015). This ambiguity blurs EDS valuation studies. For example, when a wild animal raids crops, what exactly should be assessed as the EDS: the animal eating the crops, which would be approximated by the probability that the animal visits the field; the amount of crops eaten, which would be assessed by the yield loss due to raiding; or the cost associated with this crop 
loss, which would be evaluated by the farmer's income loss? Second, it is still unclear how EDS can be accurately assessed with ES in a standardized operational framework. While several ES and EDS frameworks have been proposed (e.g. Zhang et al. 2007; Power 2010; Ma et al. 2015; Barot et al. 2017; Vaz et al. 2017; Campagne et al. 2018; Vialatte et al. 2019), they all remain elusive on how EDS interact with ES and how this interaction impacts different stakeholders' well-being, generating environmental justice and equity issues. We started from the hypothesis that a key step to address these conceptual challenges and foster integrated approaches in sustainability science would be to incorporate the EDS concept into the most seminal ES framework: the cascade model (Saarikoski et al. 2015; Costanza et al. 2017).

The central objective of this study was to conceptually clarify EDS and devise a novel framework that combines the concepts of ES and EDS - hereafter, E(D)S - then apply this in a case study to test its potential and limitations in finding innovative pathways to sustainability. In a first step, we developed an E(D)S cascade model that offers a non-ambiguous joint ES-EDS assessment working from the assumption that services and disservices are coproduced by ecosystems and people. In a second step, we conducted a qualitative E(D)S socio-cultural valuation study using the E(D)S cascade model in the Cerrado Biome in Brazil, a region where current agricultural dynamics and forest and biodiversity conservation initiatives raise significant socio-environmental challenges. To help find pathways to sustainability in this context, we explored how farmers perceived and managed the forested areas of their farms through an E(D)S lens. This allowed us to test the potential and limitations of the model in the context of our case study, which in turn highlighted some global key research questions for sustainability science that an integrated ES and EDS approach could help address.

\section{The $\mathbf{E}(\mathrm{D}) \mathrm{S}$ cascade model}

\subsection{Defining ecosystem services and disservices}

The concepts of $\mathrm{E}(\mathrm{D}) \mathrm{S}$ have been diversely defined (see Table S1), but two features appear consensual in the literature. First, E(D)S are social constructs: they do not exist independently from humans per se (in contrast to ecological structures, functions and processes), but are subjective interpretations, socially situated and constructed, of ecological phenomena (Fisher et al. 2009; Harrington et al. 2010; Spangenberg et al. 2014). A given ecological phenomenon can therefore be valued as positive (i.e. an ES) or negative (i.e. an EDS) depending on the context or person (Lyytimäki and Sipilä 2009). Second, the link between a specific E(D)S and human well-being can be direct or indirect, leading to a distinction between intermediate and final E(D)S that also depends on the context and the person (Fisher et al. 2009; Landers and Nahlik 2013; Haines-Young and Potschin 2018). For example, water quality is a final ES 
when water is used for drinking, but an intermediate ES when it supports fish populations for angling (Fisher et al. 2009).

Drawing on these considerations, we defined ES as the ecological structures, functions and processes that people recognize as supporting, directly or indirectly, their well-being. This definition implies that ES (i) must be ecological phenomena, (ii) must be viewed as positive by a person or a group of people, and (iii) can be either intermediate or final. Symmetrically, we defined EDS as the ecological structures, functions and processes that people recognize as detrimental, directly or indirectly, to their well-being. Following this definition, EDS (i) must be ecological phenomena, (ii) must be viewed as negative by a person or a group of people, and (iii) can be either intermediate or final. Intermediate EDS can be manifested through either a negative effect on an ES (e.g. crop raiding negatively affecting crop production) or a positive effect on another EDS (e.g. the spread of an invasive species can reinforce wildfire occurrence; de Wit et al. 2001). In contrast, final EDS have a direct impact on human wellbeing (e.g. wild animal attacks on humans, pollen allergens).

\subsection{Ecosystem services and disservices in the cascade model}

Fig. 1 presents the novel E(D)S cascade model illustrated through the case of a landscape where 'natural' habitats interact with human-modified habitats, such as an agricultural landscape, and where a broad range of intermediate and final $\mathrm{E}(\mathrm{D}) \mathrm{S}$ are delivered. The $\mathrm{E}(\mathrm{D}) \mathrm{S}$ cascade model is based on the following five key aspects:

(1) E(D)S are a subset of ecological structures and functions. Multiple ecological interactions and feedbacks occur within ecosystems at different organizational levels, E(D)S being those that are acknowledged as positive or negative by some individuals or groups. Of these, intermediate E(D)S influence ecological receivers (i.e. other ecological structures and functions) that are themselves positively or negatively valued by people, whereas final $\mathrm{E}(\mathrm{D}) \mathrm{S}$ influence human receivers, i.e. people who directly benefit or suffer from them.

(2) E(D)S are delivered at different organizational levels. E(D)S are provided by different ecological providers at different organizational levels (Saarikoski et al. 2015). For example, crop raiding is done by specific species, whereas erosion control relies on larger ecological units, and scenic beauty depends on a particular landscape configuration and composition.

(3) E(D)S generate material and non-material benefits and detriments. The model explicitly distinguishes $\mathrm{E}(\mathrm{D}) \mathrm{S}$ from the benefits and detriments they induce, even though this distinction is not always straightforward (Potschin-Young et al. 2018). In our definition, E(D)S are ecological phenomena, and benefits and detriments are the point at which human welfare is directly affected by them (Fisher et al. 2009). For example, forests (a provider) provide harvestable timber (an ES) that can then be processed to build fences, houses or furniture (benefits). 
(4) $E(D) S$ are joint products. An ecological provider can simultaneously deliver several E(D)S to different receivers. For example, a tree can provide shelter to a reared animal, compete with crops for light and nutrients, contribute to soil fertilization, while representing a risk to animal and human safety or property when it falls (Blanco et al. 2020b). Furthermore, a discrete ES or EDS can lead to several benefits or detriments. For example, predator attacks on humans (an EDS) can generate physical injuries as well as a feeling of insecurity (two different detriments).

(5) $E(D) S$ are coproduced by ecosystems and people. Acknowledging recent conceptual advances (Spangenberg et al. 2014; Palomo et al. 2016; Fischer and Eastwood 2016), the model considers that humans participate in the production of $\mathrm{E}(\mathrm{D}) \mathrm{S}$ through physical and cognitive processes, including the multiple values people assign to ecological phenomena. For example, a landscape or a forest is not beautiful per se, but it can be cognitively interpreted as such by people in a certain historical and cultural context.

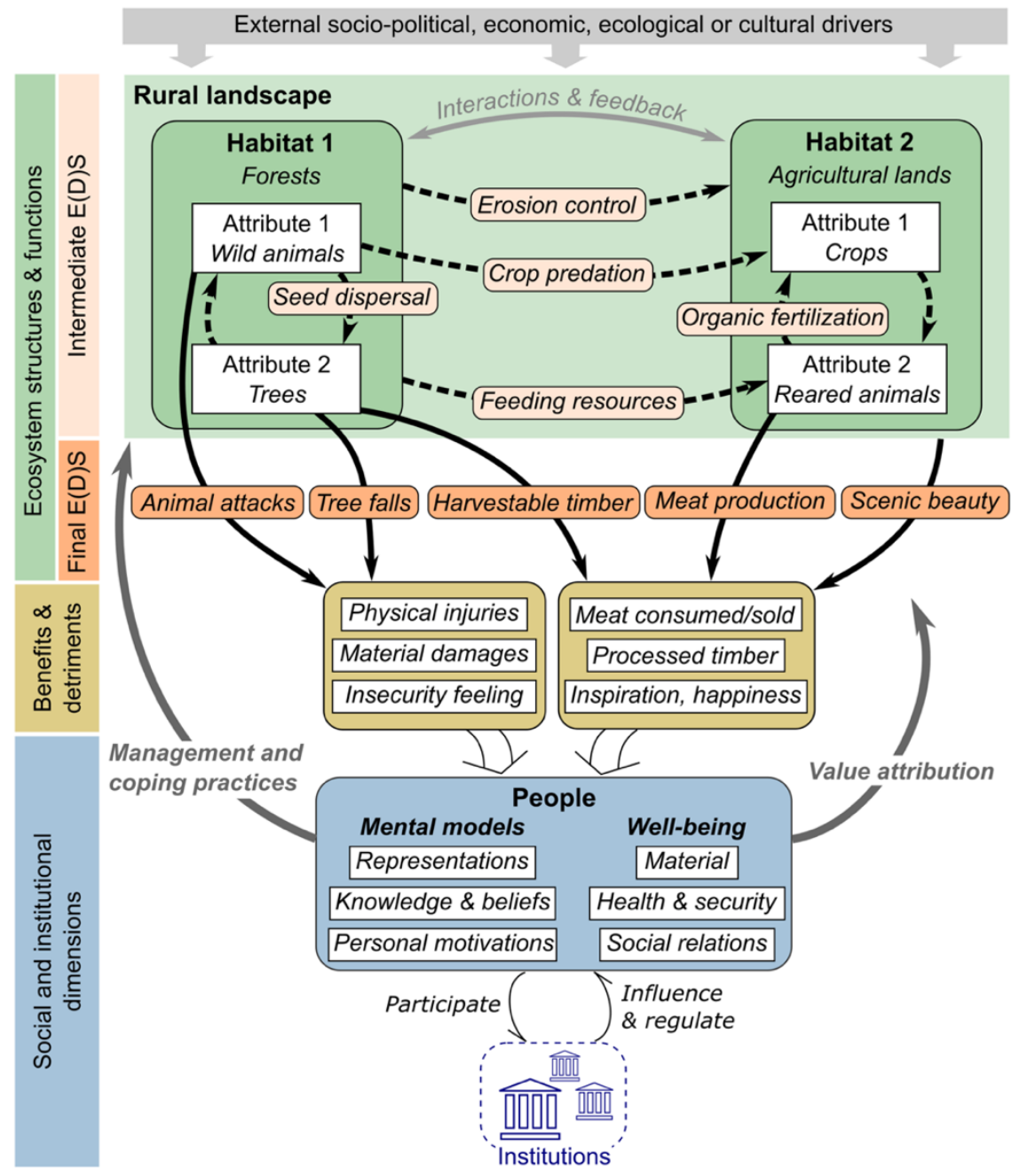

Figure 1: Ecosystem (dis)service cascade model illustrated in a typical rural landscape composed of forested and agricultural areas. Flows of intermediate E(D)S are shown as dotted black arrows; flows of final E(D)S are shown as solid black arrows. 
The design aim of the E(D)S cascade model was to offer both robustness and flexibility: clarifying $\mathrm{E}(\mathrm{D}) \mathrm{S}$ in a robust conceptual model in which services and disservices can be jointly assessed, while leaving room for people's subjectivity about the values they assign - positive or negative - to ecosystembased outcomes.

\section{Methods}

\subsection{Case study area}

The E(D)S cascade model was applied in a case study in the Mato Grosso do Sul state in Brazil, at the border of the Serra da Bodoquena National Park. This area lies within the Cerrado legal biome, but ecologically speaking is on the boundary of two major ecological formations, the Cerrado and the Atlantic Forest (Fig. S1). With its high levels of biodiversity and endemic species, the region is a biodiversity hotspot (Myers et al. 2000; Sabino and Andrade 2003; Koroiva et al. 2017). At the same time, it is a frontline for agricultural pioneers, the first of which principally created zebu cattle ranches with extensive planted pastures, expanding in the last decades into soy/maize cropping systems (Franco 2001). As a result of crop expansion, the region and its national park face both an ecological and a socioeconomic challenge as the region is an important site for ecotourism, which relies on its unique ecosystems and natural attractions (Sabino and Andrade 2003).

To promote the sustainable coexistence of agriculture and biodiversity in the region, all rural properties must comply with the Brazilian Forest Code. In the legally protected part of the Cerrado biome, this code requires rural landowners to maintain natural vegetation in Legal Reserves on $20 \%$ of their property and to preserve sensitive ecosystems by delimiting Areas of Permanent Protection on mountains, steep grades, hilltops, ridges, and around watercourses and reservoirs (Machado 2016). In their remaining lands, rural landowners are allowed to cut 10 to $20 \mathrm{~m}^{3}$ of wood per year (depending on the tree species) for self-consumption (e.g. firewood, fences, buildings), but must obtain a license to cut down larger volumes of wood (e.g. to convert a forest into a pasture or to remove scattered trees from a pasture).

As a consequence, rural forests, which encompass all the woody elements managed by farmers such as farmland forest patches, hedgerows, isolated trees and copses (Genin et al. 2013; Blanco et al. 2019b), are substantial components of the farms in the region and play an important ecological and socioeconomic role (Godoi et al. 2018). In a context of increasing tension between biodiversity conservation and crop expansion in the area, understanding how these farmers perceive and value rural forests as potential sources of $E(D) S$ is therefore vital in finding pathways toward more sustainable agricultural landscapes. 


\subsection{Data collection}

To understand farmers' perceptions of the different E(D)S associated with rural forests, we conducted semi-structured interviews at a total of 45 farms between June and July 2019. Visited farms were selected through a purposive sampling method aimed at including diverse types of farming systems rather than having a statistically balanced sample. Depending on availability and willingness to participate, at least one interview per farm was conducted with the landowner or a manager (hereafter indistinctly referred to as farmers).

The first part of each interview was structured with closed-ended questions in order to collect systematic data about farm and farming system characteristics, such as the farm surface area, the different types of crops grown or the number of head of cattle. This information was not analyzed in the study, but allowed us to ensure that our sample represented a range of farms and farmers' profiles.

The second part of each interview had a looser structure and was conducted as a discussion to enable an in-depth qualitative analysis (Russell 2011). The discussion was oriented by an interview guide that included a list of predefined questions aimed at revealing farmers' perceptions and management practices of the multiple E(D)S associated with rural forests (see S1. Interview guidelines). In particular, farmers were asked about the benefits and detriments of having forests on their farms, how they used forests (e.g. for medicinal purposes, for firewood supply, etc.), and the utility and constraints of other trees they had on their farms (e.g. isolated trees in pasture areas). Respondents were not presented with the specific concepts of E(D)S during interviews: we used common terms such as benefits, advantages, detriments and drawbacks to formulate the questions and extend the discussions. This allowed us to collect respondents' perceptions and opinions based on their own terms, rather than from a predefined list of $\mathrm{E}(\mathrm{D}) \mathrm{S}$. This loose interview strategy also allowed interviewers to adapt to respondents: for example, by inviting them to further elaborate on specific topics that inductively appeared important to them during the conversation.

The interviews were conducted in Portuguese by groups of three to four graduate and undergraduate students from France and Brazil: all were recorded and transcribed. The research was approved by the ethics committee of the Federal University of Mato Grosso do Sul (CAAE: 87336418.6.0000.0021; approval number: 3.587 .104$)$.

\subsection{Ecosystem (dis)service identification and analyses}

After collecting the interview data, we analyzed it through a mixed method relying primarily on an indepth qualitative analysis and secondarily on quantitative treatments. First, all interview transcripts were imported into NVivo (QSR International Pty Ltd. 2021), computer-assisted qualitative data analysis software that we used to encode interviews, identifying the occurrence of the themes covered in each 
interview in order to group them and draw insights from them (see Fig. S2 for the final coding scheme). We encoded all references as a service or disservice and inductively ordered them into categories. For ES, we used the Common International Classification of Ecosystem Services (CICES v5.1), which provides pre-identified ES categories as well as the possibility to add ad-hoc categories (Haines-Young and Potschin 2018). For EDS, due to the absence of a broadly accepted classification, we designed adhoc EDS categories and types based on existing studies (Shackleton et al. 2016; Blanco et al. 2020b). For each reported E(D)S, we also identified the ecological provider and receiver mentioned (or implied) by informants, and whether it was final (i.e. directly affecting humans) or intermediate (i.e. affecting another ecological feature). Finally, we encoded information about rural forest management practices and farmers' strategies in dealing with EDS.

Second, to complement this qualitative analysis, we built a database that pooled together all occurrences of the $\mathrm{E}(\mathrm{D}) \mathrm{S}$ cited by farmers and imported this into the R environment (R Core Team 2018). We used this to produce a Sankey diagram with the 'networkD3' package (Allaire et al. 2017) to visualize the main flows of $\mathrm{E}(\mathrm{D}) \mathrm{S}$ from ecological providers to social and/or ecological receivers as reported by respondents.

\section{Results}

\subsection{Farmers' perspectives on $E(D) S$ associated with rural forests}

A total of 30 ES and 18 EDS associated with rural forests were identified from our interviews with farmers, including 15 final and 15 intermediate ES, and 6 final and 12 intermediate EDS (Table 1). At an individual level, each farmer mentioned an average of 4.1 ES ( $\pm 2.3 \mathrm{SD})$ and 1.9 EDS ( $\pm 1.2 \mathrm{SD})$ during interviews. Most farmers $(N=39)$ reported both ES and EDS, with three only mentioning ES and three only mentioning EDS.

Four types of $E(D) S$ providers were identified at different organizational levels: (i) forest areas as a whole that, among other things, limit soil erosion and provide food resources to cattle, (ii) trees and forest plants that provide more specific E(D)S such as timber, shelter to cattle, or damage to buildings if trees fall, (iii) wildlife that mainly poses raiding/predation issues on crops and livestock, but is also valued for recreation and wild game provisioning, and (iv) rivers and water courses appreciated for angling, fishing, and nature-based tourism as well as drinking sources for cattle (Fig. 2). 
Table 1: List of the ecosystem services (ES) and disservices (EDS) identified from interviews conducted on 45 farms in Mato Grosso do Sul, Brazil. The ES were classified into three sections and 19 classes based on the CICES v5.1 (Haines-Young and Potschin 2018) and the EDS were classified into three sections and 10 classes.

\begin{tabular}{|c|c|c|c|c|}
\hline $\begin{array}{l}\mathrm{E}(\mathrm{D}) \mathrm{S} \\
\text { class cod }\end{array}$ & $\mathrm{E}(\mathrm{D}) \mathrm{S}$ class & $\mathrm{E}(\mathrm{D}) \mathrm{S}$ & $\begin{array}{l}\text { Type of } \\
\mathrm{E}(\mathrm{D}) \mathrm{S}\end{array}$ & $\mathrm{N}^{4}$ \\
\hline \multicolumn{5}{|c|}{ Provisioning ES: 8 ES identified within 5 different classes } \\
\hline \multirow[t]{2}{*}{ S1.1.5.1 } & \multirow{2}{*}{$\begin{array}{l}\text { Wild and domesticated plants used for } \\
\text { nutritional purposes }\end{array}$} & Harvestable fruits & Final & 14 \\
\hline & & Edible wild plants (incl. mushrooms) & Final & 3 \\
\hline \multirow[t]{3}{*}{ S1.1.5.2 } & \multirow{3}{*}{$\begin{array}{l}\text { Fibers and other materials from wild } \\
\text { plants for direct use or processing }\end{array}$} & Harvestable timber & Final & 25 \\
\hline & & Medicinal plants & Final & 4 \\
\hline & & Handcrafting materials & Final & 1 \\
\hline S1.1.5.3 & Wild plants used as a source of energy & Harvestable firewood & Final & 7 \\
\hline S1.1.6.1 & $\begin{array}{l}\text { Wild animals used for nutritional } \\
\text { purposes }\end{array}$ & Edible wild animals & Final & 4 \\
\hline S1.2.1.1 & $\begin{array}{l}\text { Seeds, spores and other plant materials } \\
\text { collected for maintaining or } \\
\text { establishing a population }\end{array}$ & Harvestable seeds & Intermediate & 1 \\
\hline \multicolumn{5}{|c|}{ Regulating \& maintenance ES: 16 ES identified within 11 different classes } \\
\hline S2.2.1.1 & Control of erosion rates & $\begin{array}{l}\text { Prevention and reduction of soil } \\
\text { erosion }\end{array}$ & Intermediate & 8 \\
\hline S2.2.1.3 & $\begin{array}{l}\text { Hydrological cycle and water flow } \\
\text { regulation }\end{array}$ & Maintenance of water sources & Intermediate & 1 \\
\hline S2.2.1.4 & Wind protection & Windbreak effect & Intermediate & 2 \\
\hline \multirow[t]{2}{*}{ S2.2.2.3 } & $\begin{array}{l}\text { Maintaining nursery populations and } \\
\text { habitats }\end{array}$ & $\begin{array}{l}\text { Habitat and feeding resources for } \\
\text { reared animals }\end{array}$ & Intermediate & 15 \\
\hline & & $\begin{array}{l}\text { Habitat and feeding resources for } \\
\text { wildlife }\end{array}$ & Intermediate & 3 \\
\hline S2.2.3.1 & Pest control & Pest and predator control & Intermediate & 3 \\
\hline S2.2.3.2 & Disease control & Disease and parasite control & Intermediate & 1 \\
\hline \multirow[t]{2}{*}{ S2.2.4.1 } & \multirow{2}{*}{$\begin{array}{l}\text { Weathering processes and their effect } \\
\text { on soil quality }\end{array}$} & Maintenance of soil moisture & Intermediate & 2 \\
\hline & & Physical decompaction of soils & Intermediate & 1 \\
\hline S2.2.4.2 & $\begin{array}{l}\text { Decomposition and fixing processes } \\
\text { and their effect on soil quality }\end{array}$ & Decomposition of plant residue & Intermediate & 2 \\
\hline S2.2.5.1 & $\begin{array}{l}\text { Regulation of the chemical condition } \\
\text { of freshwaters by living processes }\end{array}$ & Maintenance of river quality & Intermediate & 2 \\
\hline S2.2.5.2 & $\begin{array}{l}\text { Regulation of the chemical } \\
\text { composition of the atmosphere and } \\
\text { oceans }\end{array}$ & Mitigation of air pollution & Final & 1 \\
\hline \multirow[t]{4}{*}{ S2.2.6.2 } & $\begin{array}{l}\text { Regulation of temperature and } \\
\text { humidity }\end{array}$ & Sheltering effect for reared animals & Intermediate & 32 \\
\hline & & Maintenance of air humidity & Intermediate & 2 \\
\hline & & $\begin{array}{l}\text { Sheltering effect for planted crops } \\
\text { and pastures }\end{array}$ & Intermediate & 1 \\
\hline & & Sheltering effect for humans & Final & 1 \\
\hline
\end{tabular}

Cultural ES: 6 ES identified within 4 different classes 
S3.1.1.1 Characteristics of living systems that enable activities promoting health, recuperation or enjoyment through active or immersive interactions

S3.1.1.2 Characteristics of living systems that enable activities promoting health, recuperation or enjoyment through passive or observational interactions

S3.1.2.1 Characteristics of living systems that enable scientific investigation or the creation of traditional ecological knowledge

S3.2.2.1 Characteristics or features of living systems that have an existence value
Opportunities for nature-based

Final

8

ourism

Opportunities for angling

Final

4

Opportunities for walks and

Final

5 observations

Overall natural beauty

Final

5

Habitats, plants and animals of special interest

Final

Existence value of natural

Final

Material EDS: 3 EDS identified within 3 different classes

$\begin{array}{lllll}\text { D1.1 } & \text { Impact on buildings } & \text { Risk of damage to buildings } & \text { Final } & 1 \\ \text { D1.2 } & \text { Impact on material assets } & \text { Risk of damage to fences } & \text { Final } & 2 \\ \text { D1.3 } & \text { Raiding by wild animals } & \text { Animals stealing food from houses } & \text { Final } & 1\end{array}$

Indirect EDS: 12 EDS identified within 5 different classes

D2.1.1 Causes of reduced terrestrial plants grown for nutritional purposes

D2.1.2 Causes of reduced animals reared for nutritional purposes

D2.1.3 Uncontrolled crossbreeding between wild and domestic animals

D2.1.4 Reduced potential of productive habitats

D2.2.1 Negative impact on hydrological cycle and water flow

\section{Raiding of cultivated crops \\ Weed dissemination and development into agricultural areas Raiding of edible fruits}

Predation on reared animals

Competition with reared animals for feeding resources

Disease and parasite transmission to reared animals

Risk of tree falls on reared animals

Unsuitable habitat conditions for reared animals

Crossing of boars with domestic pigs Intermediate

Degradation of agricultural soils by Intermediate wildlife

Physical obstacles to agricultural machinery

Reduction of water sources

Intermediate

Intermediate

Intermediate 1

Intermediate 30

Intermediate 3

Intermediate 1

Intermediate 1

Intermediate 1

Intermediate 1

Intermediate 1

Health \& security EDS: 3 EDS identified within 2 different classes

\begin{tabular}{|c|c|c|c|}
\hline D3.1 & Dangerous physical contacts & Animal attacks on people & Final \\
\hline & & Animals causing traffic accidents & Final \\
\hline D3.2 & Disease and parasite transmission & $\begin{array}{l}\text { Zoonotic disease transmission to } \\
\text { humans }\end{array}$ & Final \\
\hline
\end{tabular}

ๆ The $\mathrm{N}$ column represents the number of farms where the ES or EDS was mentioned by respondents.

The most cited ES $(N=32)$ was the sheltering effect of rural forests for reared animals, including protecting cattle from sun, wind and cold. This ES motivated farmers to maintain trees in their pastures, mostly in the less productive areas: "We maintain a patch of forest in almost all winter pastures to 
protect animals from wind, cold, sun, etc. [...]. These areas are generally stony, so pasture grass does not grow. It would be useless to remove these forest patches as we would not be able to plant anything there anyway." (F-Bon-30). In addition to providing shelter, forests were appreciated as habitats with feeding resources for cattle ( $N=15)$, enabling diet diversification with tree fruits and leaves and different types of grass. Letting cattle graze in forests was also considered beneficial to tree seed dissemination: "We know that ruminants and other animals eat and sow seeds [...]. Here is a bocaiuva [Acrocomia aculeata]: there are many of them all over the farm, thanks to animals." (F-Bon-28).

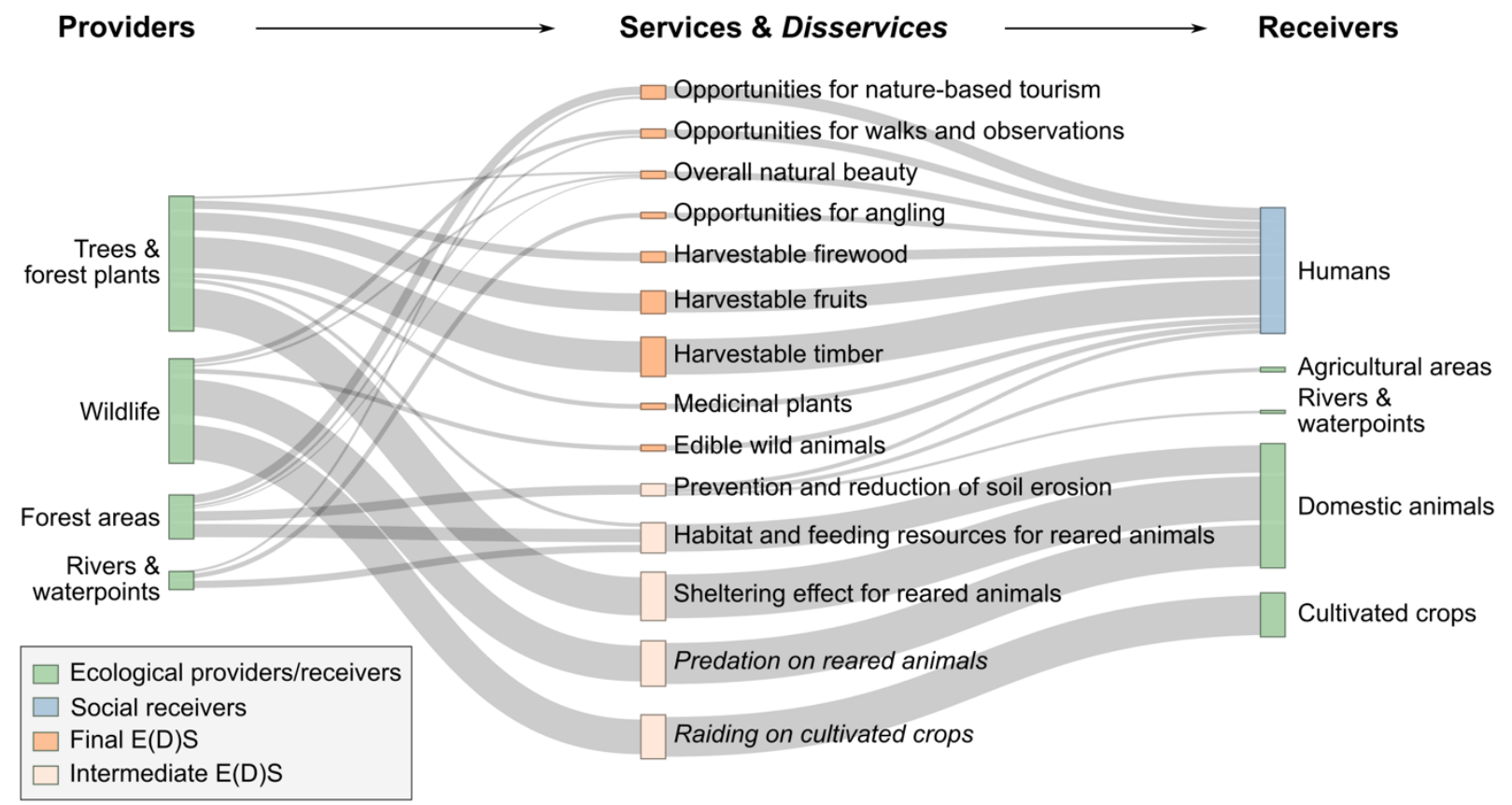

Figure 2: Sankey diagram illustrating the main flows of services and disservices (in italics) between providers (left) and receivers (right) according to their saliency in interviews with farmers. For the sake of visibility, only the services and disservices mentioned by $>3$ respondents are shown, and the feedback loops from receivers to providers are not represented.

Regarding provisioning ES, dead trees and trees cut down during pasture clearing and forest conversion were appreciated as sources of firewood $(N=7)$ and, more importantly, timber $(N=25)$ for building fences and houses. However, 8 farmers explicitly stated that they tended to buy firewood rather than using their own wood due to the low price of purchased firewood and the difficulty of obtaining a permit to cut down trees. Fruit trees were also frequently cited as provisioning ES $(N=14)$, either planted tree species such as citrus (Citrus spp.) or wild native species such as guavira (Campomanesia xanthocarpa) and jatoba (Hymenaea courbaril).

Cultural ES were less salient in interviews, although farmers mentioned the importance of forested areas for nature-based tourism $(N=8)$, for the overall beauty of the area $(N=5)$, and for observation and walking 
experiences $(N=5)$. Conversely, several ES that are known to be key to agricultural activities, such as the maintenance of water sources and disease control, were rarely mentioned (Table 1).

In terms of EDS, the farmers mentioned wild animals living in forests and their predation of cattle $(N=30)$ and raiding of crops $(N=27)$. In particular, jaguars (Panthera onca) were reported as preying on calves and, to a lesser extent, adult zebus: "Jaguars attack 0- to 3-month-old calves and can kill up to two calves per day [in the period when the calves are nursing]. Last year, I lost four, and already 26 this year. They also attack one to two adult cows per year." (F-Bon-01). However, some farmers stated that cattle predation did not significantly impact their activities: "As [jaguars] only attack one calf every 2 to 3 months, considering the size of the farm, it's not a big problem." (F-Bon-12). Crop raiding was also considered a significant EDS, in particular for maize, which is eaten by different wild pig species, including collared peccary (Pecari tajacu), white-lipped pecary (Tayassu pecari), and wild boars (Sus scrofa). Certain farmers stated that the resulting crop damage was significant: "In general, over 100 hectares [of maize] - one-third of the area - is destroyed." (F-Bon-22). Other farmers said they were little impacted: "Pigs are problematic, but not that much: from over 1000 hectares they might eat two." (F-Bon-28). These two contrasting perspectives might be partly explained by how farmers deal with EDS (see section 4.3).

\subsection{Farmers' perspectives on changes in $E(D) S$}

Respondents pointed to the expansion of soy cultivation as a key driver of change in the region. According to them, this expansion involves the conversion of either pasture or forest into cultivated areas, which is regulated by Brazilian legislation, with cascading effects on E(D)S and associated detriments and benefits (Fig. 3).

The first cascading effect reported by respondents was related to converting forest into cultivated areas and pastures, leading to a decrease in natural habitats and an increase in livestock predation: "Wild animals attack domestic animals because they have no other animals to prey on anymore. They do not have food in nature anymore because half of the animals have been killed by humans, and the other half had to leave because there are no more natural areas." (F-Bod-13). According to respondents, crop expansion mainly occurs over old pastures (which are less expensive to convert than forests), putting pressure on remaining forests for the creation of new pastures, and therefore on wildlife habitats. This results in less wild prey (in particular for jaguars), making carnivores more prone to prey on farm animals (Fig. 3). 


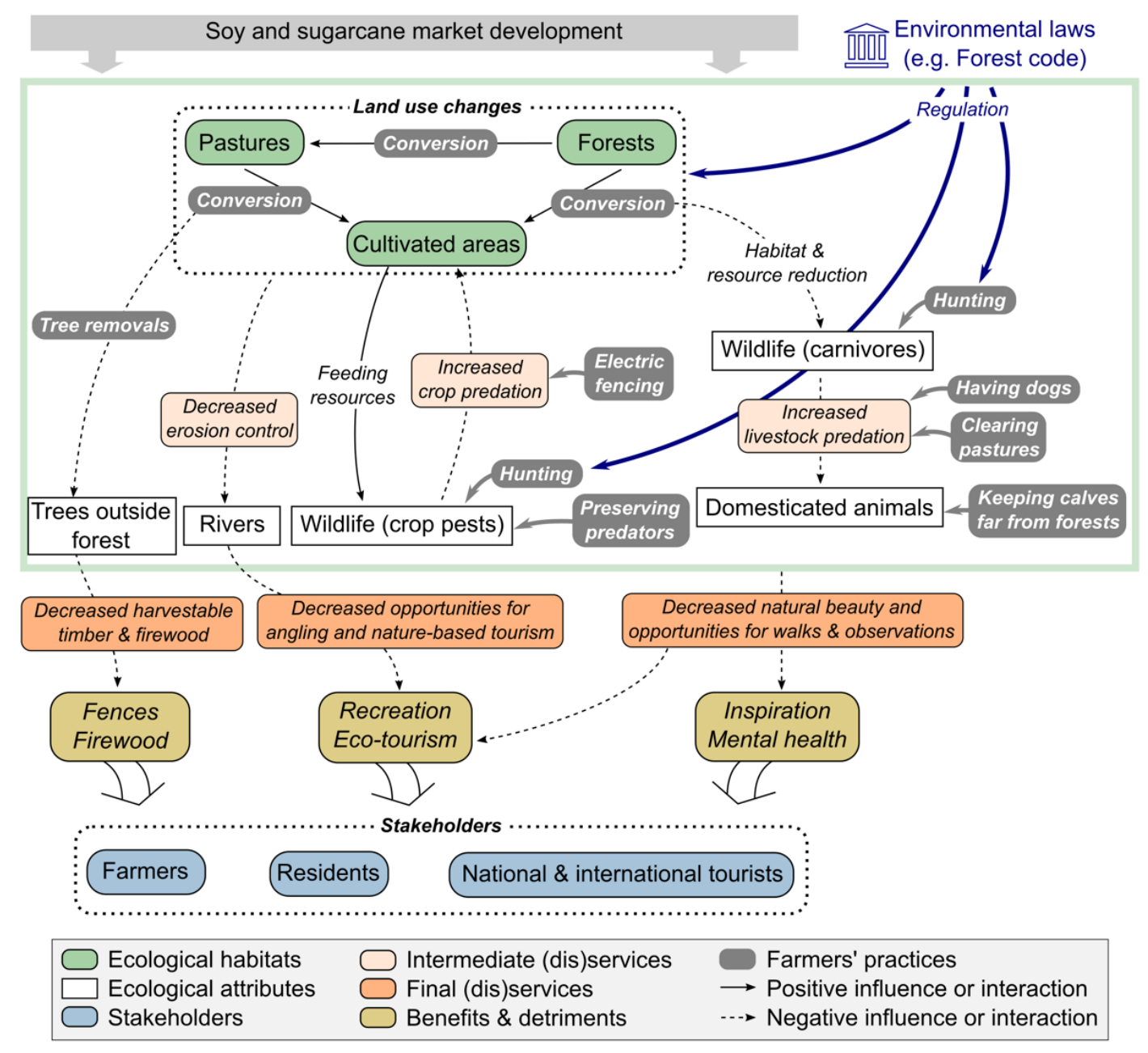

Figure 3: Diagram summarizing the cascading effects of external factors on land use and subsequent ecological attributes and processes, key ecosystem services and disservices, and associated benefits and detriments in the case study area. This diagram reflects the perspectives of the interviewed farmers on these dynamics and focuses on the main services and disservices reported by respondents. It highlights the farmers' practices that either participate in the different dynamics or that aim at coping with main ecosystem disservices.

The second cascading effect was related to the expansion of cultivated areas, which caused a decline in erosion control: "The Prata River is polluted, starting $30 \mathrm{~km}$ upstream from the farm, an area where the quantity of cultivated areas has increased, which causes landslides and dirty water in the river. [...] This has impacted tourism because the water was dirty during the rainy season, so we couldn't practice certain activities on the farm such as diving." (F-Jar-03). In a region where tourism is an important economic sector and many farms offer tourist attractions and facilities, this reduced erosion control was heavily incriminated for its impact on river quality and on dependent tourist activities such as snorkeling and swimming (Fig. 3). According to respondents, there was also a vicious circle between crop expansion, increased invasive species and increased crop raiding. The main culprits are pig species, especially wild boar, which is an invasive non-native species in the region: "The forest is a refuge for animals and maize fields provide them food. [...] They were less interested in [grazing] pastures - we 
hardly used to see them." (F-Bon-19). This problem was reinforced by the fact that crops are being expanded in areas where there are only a few remnants of natural habitats, and thus few wild predators: "Do you think pigs prefer going to the mountain range over there or to eat maize here? They will come here since there is abundant food and no predators. Why are pigs a problem? Because today, we do not hunt them." (F-Bon-28).

\subsection{Farmers' practices for coping with EDS}

Farmers are actors in the ongoing changes in land use, but they also adapt their practices to the changes they perceive (Fig. 3). In our analysis, we focused on the preventive and regulating practices they use to cope with EDS and their increased incidence.

The preventive practices were principally aimed at decreasing farm vulnerability and exposure to EDS. To prevent cattle predation, farmers stated they (i) own dogs, whose presence deters carnivores from entering farms, (ii) maintain clear, open pastures so predators have no hiding places and are more visible, and (iii) keep calves away from forests and close to houses, where predators are less prone to approach, as explained by several farmers: "We have started to manage livestock in a different way. As jaguars were eating calves, we moved them away from forest areas and put the oldest cows close to forests." (FBon-29). Farmers also rethought the location of crops: "The first two years we cultivated crops here, half of the maize was eaten by pigs because we didn't pay attention. Now we avoid cultivating close to forests." (F-Bon-30). In addition, electric fencing was advocated by some to protect crops from predators, although several farmers were not convinced by its effectiveness: "[Wild animals] enter the fenced fields, then they can't get out and are left stuck inside." (F-Bon-29). Overall, our qualitative analysis suggested that the feasibility and reliability of preventive practices were partly influenced by the location of the farm, such as the proportion of areas far from forests and the local predation pressure, explaining the different points of view highlighted in section 4.1.

In addition to preventive practices that concerned farm management choices, farmers stated that they implement regulating practices that aim to mitigate EDS by acting on their ecological providers. For example, many cited the necessity to hunt pigs (peccaries and wild boars) and jaguars to regulate their populations and reduce crop raiding and livestock predation. However, environmental laws ban hunting native species, except for self-defense, and only allow hunting invasive species such as wild boar. While the majority of respondents said they comply with these laws, some indicated that they do hunt: "The easiest way [to hunt jaguars] is when they kill calves. They take and hide the carcass, which can be tracked, and they return to eat it when they get hungry. So it's possible to ambush them." (F-Bon-01). However, two farmers involved in crop production stated they wish to increase the population of natural predators to control certain EDS providers: “Jaguars prevent peccaries from entering the fields, but 
there are not enough of them to prevent damage from peccaries. It would be necessary to breed jaguars to no longer have peccaries on the farms." (F-Bon-10).

\section{Discussion}

\subsection{Potential and limitations of the E(D)S cascade model}

After more than a decade of debates around the EDS concept, the idea of taking into account the negative impacts of ecosystems on human well-being as well as their positive contributions has gained momentum in sustainability research (Díaz et al. 2018; Blanco et al. 2019a). The E(D)S cascade model we developed seems to provide a robust and operational, yet flexible, model to allow this joint assessment.

In our case study, the model proved useful to shed light on the diverse synergies and trade-offs that occur between ES and EDS and, importantly, on the distinction between intermediate and final ecosystem disservices. While Shackleton et al. (2016) highlighted the difference between direct and indirect EDS, the authors did not discuss its symmetry with intermediate and final ES nor its analytical implication: from the standpoint of environmental accounting, where double counting must be avoided, only final E(D)S should be considered (see also Fisher et al. 2009). This is because the influence of intermediate EDS - i.e. the diminution of an ES or the reinforcement of another EDS - would already be accounted for by final E(D)S. For example, the tangible cost of livestock predation is already taken into account when valuing the benefits derived from meat production. However, livestock predation should sometimes be considered as a final EDS for its psychological consequences (Methorst et al. 2020). Thus, just as with ES (Fisher et al. 2009), the context and objectives of the analyst determine whether a given EDS is final or intermediate. Of course, this distinction between intermediate and final E(D)S might not always be critical to all biophysical and socio-cultural valuation studies. For example, in our case study, the role of rural forests in controlling erosion was appreciated by farmers as it allowed maintaining fertile agricultural land, clean rivers for snorkeling activities, and, more generally, limited gullies and riverbank alteration. Thus, in these farmers' eyes, erosion control is both an intermediate and a final ES depending on the benefit considered. In this case, the analysis of farmers' perspectives does not absolutely require that the analyst make the distinction between an intermediate or final $\mathrm{E}(\mathrm{D}) \mathrm{S}$.

The model also helped to clarify (i) what constitutes an EDS and (ii) the delineation between ecological phenomena, EDS, and associated detriments or costs. In the existing literature, there is persisting ambiguity on these two aspects. For example, fear of crime in urban green spaces is sometimes considered as an EDS (e.g. Pinto et al. 2021). Yet this is not an ecological phenomenon, so it does not fall into the scope of the EDS definition proposed in our model (see section 2.1). While social phenomena can influence the quality of people's experience with nature, we argue that it is not useful 
to conflate this with EDS and that another terminology or concept should be used to designate these social impacts. Furthermore, even in recent literature, the term EDS is used to designate negative ecological phenomena and costs indistinctively. For example, in Zhen et al. (2021), soil acidification and morbidity of people caused by different types of agricultural systems are both considered as EDS. However, the latter is neither a phenomenon arising from the ecosystem, nor is it caused by an ecological phenomenon, since it is linked to the use of pesticides. As suggested by previous authors (Shackleton et al. 2016), such phenomena that result from human (mis)management of ecosystems should not be considered as EDS, nor accounted as costs emanating from ecosystems.

The stricter definitions chosen for our model aim to encourage researchers and practitioners to pay greater attention to how they use the EDS concept for the sake of its overall credibility and consistency. However, we acknowledge that delineating EDS from associated costs and detriments, or delineating EDS from certain social-based phenomena, may not always be obvious or straightforward, as is the case for ES (Potschin-Young et al. 2018). Nonetheless, it seems vital to avoid E(D)S concepts becoming panchrestons, i.e. terms that mean so many things to different people that they are conceptually and empirically useless (Simberloff 2014). We therefore argue that researchers should be more rigorous and explicit about their choices in how they delimit E(D)S from other phenomena, which will help in conducting comparative analyses of different case studies and in scaling up local findings.

In terms of limitations of our E(D)S cascade model, the first is that it is not spatially explicit and does not fully unpack the social and institutional arrangements that mediate E(D)S delivery, such as multiple stakeholder interactions and formal and informal rules and norms. This limitation could be overcome by combining the model with existing $\mathrm{E}(\mathrm{D}) \mathrm{S}$ frameworks that aim to deal with these aspects (Summers et al. 2012; Barnaud et al. 2018; Vialatte et al. 2019). Secondly, the model is not intended to be used as an objective, dichotomous delineation of the relationship between people and ecosystems. Its goal is to orient the analysis of people's subjective opinions about their environment in order to provide more balanced and inclusive assessments of nature's positive and negative impacts. The aim of the model is to help reveal consensual and non-consensual views about ecosystems, a necessary starting point to identify potential tensions and conflicts and ultimately shared solutions toward sustainability (Buijs et al. 2011). To avoid dichotomy, it is critical to distinguish between $E(D) S$ providers and $E(D) S$ themselves, which allows identifying nuances in what humans consider as 'good' or 'bad'. As illustrated by our case study, many ecological phenomena simultaneously produce multiple ES and EDS, and the farmers we interviewed were perfectly aware of this duality. Destroying an ecosystem to remove an EDS might result in the loss of beneficial ES, while conversely, focusing on a given ES might lead to unanticipated EDS and costs (Friess 2016; Stokely and Betts 2020). The model is designed to help identify and navigate such complex trade-offs and synergies. 
Finally, the E(D)S cascade model offers a conceptual foundation that could be the basis for designing a broadly relevant EDS typology as already exists for ES. This could also be relevant beyond the strict field of ES research, in particular in the nature's contributions to people (NCP) framework. This recent approach emphasizes the necessity of accounting for both positive and negative impacts of nature (Díaz et al. 2018). Yet it also tends to put negative impacts 'behind the scenes' in its 18 identified NCP categories: detrimental aspects of nature are included within positive contributions, such as NCP category \#10, which includes the regulation of detrimental organisms. In order to reach the equal consideration of both positive and negative impacts of nature as some authors advocate (Schaubroeck 2017), putting them on the same analytical level is critical, which is the aim of this $E(D) S$ cascade model.

\subsection{Farmers' perceptions of rural forests: unpacking a complex context-specific relationship}

In our qualitative socio-cultural valuation study in a region of the Mato Grosso do Sul state in Brazil, the model helped to identify farmers' systemic and dynamic visions of the benefits and detriments they associate with rural forests. To our knowledge, this topic has not been covered by previous research in this region; this is why we chose a qualitative approach and open-ended interview techniques. These were ideal to provide a preliminary understanding of the topic and its delimitation, but were not suited to detailed quantitative analyses. So, while the case study did not provide definitive results, the findings could be helpful to future research and more systematic and quantitative approaches that would allow some of our preliminary results to be confirmed or refuted. In particular, two key aspects could be further explored: (i) the extent to which individual farmers' perceptions of $E(D) S$ are mediated by either farming practices and/or personal factors, and (ii) the relationship between farmers' perceptions and the local socio-political context.

With this proviso in mind, we found that most farmers acknowledged the duality of the impacts of rural forests, as individuals reported both ES and EDS. A few farmers mentioned only ES or only EDS, but this was mainly due to the limitations of the loose interviewing method we chose. As interviewers oriented the discussions based on the topics that inductively appeared, all interviews could not systematically cover all possible topics, in particular because of farmers' time constraints. Despite this methodological limitation, we found that farmers tended to report a larger number of ES than EDS, which is consistent with similar studies in other contexts (Ango et al. 2014; Blanco et al. 2020b). Brazilian farmers especially emphasized regulating ES and indirect EDS that impacted their crops and livestock, confirming their expertise and focus on their main source of income, but also their subjectivity. Interestingly, a larger number of intermediate E(D)S than final E(D)S were mentioned by farmers, which was even more salient for EDS than ES (Table 1). This result suggests that the negative effect of rural forests on farmer well-being is mostly indirect (i.e. through agricultural activities) rather than direct. Along with the higher number of ES mentioned than EDS, the findings also suggest that the 
overall (or 'net') contribution of rural forests to these farmers is positive, which is a promising lever to foster better coexistence between agriculture and biodiversity in the region.

Yet our results also tend to corroborate the hypothesis that, for a similar intensity, EDS might have a greater influence on farmers' perceptions, attitudes and behaviors than ES (also observed in Kansky and Knight 2014; Blanco et al. 2019a). When asked about rural forests, farmers were more prone to discuss negative aspects, although overall they cited less EDS than ES (in number). In addition, the frequent mention of livestock predation contrasts with the low abundance of large predators found by ecological surveys in the region (Cáceres et al. 2007). Livestock predation issues seemed to be overstated considering the negligeable share of herds effectively lost.

Two complementary hypotheses, one cognitivist and one political, may explain this imbalance between farmers' discourse and biophysical phenomena. First, neuroscientific research has shown that humans tend to have a stronger reaction to negative vs. positive stimuli, known as the 'negativity bias' (Norris 2019). In our case, this cognitive bias could explain why farmers gave disproportionate attention to certain EDS compared to their actual manifestation. It is valuable to highlight the existence of such negativity bias, as this could further challenge biodiversity conservation efforts (Buijs and Jacobs 2021). Indeed, while it is often argued that ES could help counteract certain EDS in order to foster more sustainable human-nature relationships (Teixeira et al. 2020), negativity bias might mean that higher levels of ES are necessary to compensate for a given level of EDS. While further quantitative research is required to confirm whether negativity bias affects how people perceive and react to ecosystem-based stimuli, this could open new transformational avenues: if verified, this hypothesis implies that decreasing actual and perceived EDS could be a powerful driver in creating more sustainable humannature relationships - even more powerful than increasing actual and perceived ES.

In addition to this cognitivist hypothesis, the local socio-political context around rural forest conservation in Brazil might be a key factor in farmers' focus on EDS. The Brazilian Forest Code requires farmers in the study region to maintain native vegetation in Areas of Permanent Protection and in Legal Reserves. Furthermore, the creation of the Serra da Bodoquena National Park in 2000, partly on private land, has been a source of tension between farmers and environmental agencies. In this context, farmers tended to have a negative attitude toward forest conservation policies that substantially impact the proportion of land they can use for agriculture: "Brazilian farmers suffer from environmental issues [...]. Over the 100 hectares I was talking about, 80 hectares remain after you remove Legal Reserves, and then you remove some land where there are rivers, so 70 hectares remain, and if you have hills, then you eventually can only use 50 hectares." (F-Bon-28). The latent conflict between farmers and environmentalists in the region might influence the former's attitudes toward forests and biodiversity, and the attention they pay to associated E(D)S, as has been shown in other contexts with human-wildlife conflicts (Hodgson et al. 2020). One study has found that when people are affected by 
EDS, they tend to have less positive attitudes toward biodiversity conservation (Nyhus et al. 2000). This suggests that focusing on EDS and finding ways to reduce these could help improve local support for conservation initiatives. In our case study, these two cognitivist and socio-political hypotheses call for further research to better understand the many factors that influence farmers' relationships with rural forests, which might include (i) the farming systems (which are more or less vulnerable to different EDS), (ii) farmers' personal views and history (which might influence farmers' tolerance to EDS) and (iii) farmers' relationships with local stakeholders (which might influence farmers' socio-political discourse and opinions).

Finally, we found that some E(D)S were absent from farmers' discourse. This was the case for certain regulating ES such as the maintenance of water sources and disease control, which were perhaps too indirectly connected to rural forests in farmers' eyes to be mentioned. This was also the case for cultural EDS, which were totally absent (Table 1). This result may be explained by the ambiguity around this EDS category, which has also been highlighted for cultural ES. Beyond the argument that the 'cultural ES' category tends to isolate cultural aspects that transcend all ES categories - many cultural benefits being associated with provisioning and regulating ES (Chan et al. 2012) - it has also been argued that cultural ES should be understood as benefits rather than services (Fisher et al. 2009). For example, enjoying a walk in the forest is a benefit (not an ecological phenomenon that provides a service). The provider of this benefit is the forest, at least as long as there are walking trails in it. According to the CICES, the ES associated with this benefit is the "opportunity for walks" that the forest offers (HainesYoung and Potschin 2018). Yet this example shows that differentiating the ES provider from the ES, and the ES from the benefit, is particularly tricky for cultural ES. Similarly, in our study, farmers raised the fear of being attacked by predators, which we considered as a detriment rather than a cultural EDS. The EDS associated with this detriment would be the chance of being attacked, but this EDS was already accounted for in the EDS 'Animal attacks on people' (D3.1, Table 1). Thus, in this case the E(D)S cascade model identifies only one EDS - i.e. animal attacks on people - producing two types of detriments: physical injuries and a feeling of insecurity. This explains the absence of cultural EDS in our study, but also highlights the need to elaborate a consistent EDS typology as a next step to further operationalize the E(D)S cascade model.

\subsection{Taking into account ecosystem disservices: an alternative pathway toward sustainability}

The information identified through the use of our model in the case study shows promise in helping to address sustainability issues. The model allowed us to demonstrate that in farmers' eyes, rural forests are a major source of ES and that EDS are more marginal (at least in number). This result offers a potential avenue to go beyond the traditional conflict between productive agriculture and biodiversity 
conservation, and to move forward together on reconciling these two key socio-environmental challenges.

The analysis also identified a vicious circle between crop expansion, soil erosion and invasive species that could have major economic and ecological consequences in the future. The conversion of pastures to cultivate maize and soy was reported as altering soil erosion control and river quality for snorkeling, while contributing to the proliferation of wild boar. Yet whereas Brazilian environmental law is very strict regarding deforestation, pasture conversion into cropland is less restricted, and the farmers we interviewed did not mention having any difficulty obtaining the required permit (contrary to obtaining authorization for clearing forest patches). In this sense, the application of the E(D)S cascade model allowed us to point to a legislative blind spot and to raise the alarm about the very concrete consequences that crop expansion could have in the region, namely the decrease of the area's tourism value, the proliferation of certain invasive species, and the potential exacerbation of human-wildlife conflicts.

The findings also showed that the capacity of ecosystems to provide E(D)S is closely linked with agricultural management practices (Stokely and Betts 2020). In particular, our results highlighted that farmers use different preventive and regulating practices to mitigate EDS that do not necessarily interfere with ecological providers (Ango et al. 2014). For example, changing the location of crop fields or areas for raising calves within farms allowed crop raiding and livestock predation to be reduced without impacting peccaries and jaguars. Highlighting such adaptive practices, and better supporting them through ad-hoc incentives (Marchini et al. 2011), could be a promising strategy to improve the local coexistence of agriculture and biodiversity.

In a more global perspective, reinforcing research on EDS could lead to a major shift in sustainability research and policy paradigms. The ES concept was essentially introduced to raise the awareness of people and policymakers on the many benefits provided by ecosystems. The main idea was to convince human societies that biodiversity conservation was a sound strategy, even on a purely economic basis. To complement this idea, the EDS concept acknowledges that biodiversity conservation can also generate costs for certain people, which is critical to consider and evaluate to avoid environmental inequalities (McElwee 2010). This concept also allows a better understanding of the factors that undermine biodiversity conservation, and the reasons why people are sometimes skeptical about it and might act against it. As the case study demonstrated, this focus can help find alternative solutions that promote sustainability, such as those implemented by the farmers who adapted their practices to reduce their vulnerability to EDS without necessarily killing the animals that caused crop or livestock losses. Giving more consideration to EDS would allow a two-fold strategy for biodiversity conservation: (i) reinforcing ES and associated benefits, in the hope that this contributes to preserving ecosystems, and (ii) reducing EDS and associated costs, helping people to become less vulnerable to EDS in a sustainable manner. Ultimately, policymakers would play a key role in supporting the adoption of preventive 
practices that aim to decrease people's vulnerability and exposure to EDS, while fighting against practices that participate in ecosystem degradation. This would represent a significant change in current sustainability paradigms.

\section{Conclusion}

Providing more inclusive and balanced assessments of the multiple impacts of ecosystems on human societies is a major challenge in sustainability science. The novel cascade model devised in this study integrates both ES and EDS so both can be jointly assessed. This was tested in a case study to explore Brazilian farmers' relationships with rural forests in a region in Mato Grosso do Sul. The model proved valuable in showing that these farmers associate a broad spectrum of ES and EDS with rural forests, revealing their perspectives about how rural forests interact, positively and negatively, with their farms. The results highlighted that just like ES, ecosystem disservices are coproduced by ecosystems and people. They also revealed ways how the EDS perceived as most problematic can be mitigated by adapting human practices, in particular farming systems, without impacting biodiversity. Ultimately, this novel E(D)S cascade model offers a conceptual basis to better understand socio-ecological systems and better foster the integration of EDS in ES research, helping to open new avenues toward more effective sustainability policy.

\section{Acknowledgements}

This research was funded by the Brazilian National Council for Scientific and Technological Development (CNPq) (in particular through grants to FLS: Process 301306/2018-4, and to FOR), and by the Regional Council of the Pays de la Loire (France) through the CASEST (Anthropogenic Constraints to Tropical Savanna Socio-Ecological Systems) project. BB received a Rhodes University Postgraduate Scholarship (number: 2000108). We also received financial support from the Wetlands International office in Campo Grande and the MUPAN (Women in Action in the Pantanal) association. We would also like to thank all those from the farms we visited who accepted to be interviewed, as well as Sandro Roberto da Silva Pereira from the Chico Mendes Institute for Biodiversity Conservation (ICMBio) and Nino Rodrigo from the Brazilian Agency for Agricultural and Rural Development (AGRAER) for their valuable help in the field. Finally, we are grateful to all those who participated in the interviews with farmers, as translators or assistants, including Aurélie de Palmas, Inès Fillon, Fabio Bolzan, Guilherme Dalponti, Aline Giroux, and Dinah Madruga. 


\section{References}

Ainscough J, de Vries Lentsch A, Metzger M, et al (2019) Navigating pluralism: Understanding perceptions of the ecosystem services concept. Ecosyst Serv 36:100892. https://doi.org/10.1016/j.ecoser.2019.01.004

Allaire JJ, Gandrud C, Russell K, Yetman CJ (2017) networkD3: D3 JavaScript Network Graphs from R

Ango TG, Börjeson L, Senbeta F, Hylander K (2014) Balancing ecosystem services and disservices: Smallholder farmers' use and management of forest and trees in an agricultural landscape in southwestern Ethiopia. Ecol Soc 19:art30. https://doi.org/10.5751/ES-06279-190130

Barnaud C, Antona M (2014) Deconstructing ecosystem services: Uncertainties and controversies around a socially constructed concept. Geoforum 56:113-123. https://doi.org/10.1016/j.geoforum.2014.07.003

Barnaud C, Corbera E, Muradian R, et al (2018) Ecosystem services, social interdependencies, and collective action: a conceptual framework. Ecol Soc 23:art15. https://doi.org/10.5751/ES-09848-230115

Barot S, Yé L, Abbadie L, et al (2017) Ecosystem services must tackle anthropized ecosystems and ecological engineering. Ecol Eng 99:486-495. https://doi.org/10.1016/j.ecoleng.2016.11.071

Blanco J, Dendoncker N, Barnaud C, Sirami C (2019a) Ecosystem disservices matter: Towards their systematic integration within ecosystem service research and policy. Ecosyst Serv 36:100913. https://doi.org/10.1016/j.ecoser.2019.100913

Blanco J, Moreau C, Guerbois C, et al (2020a) La biodiversité, une ressource, mais aussi un fardeau ? Intérêt et limites des notions de services et disservices écosystémiques pour repenser les interactions nature-sociétés dans les territoires ruraux. VertigO. https://doi.org/10.4000/vertigo.29079

Blanco J, Sourdril A, Deconchat M, et al (2020b) How farmers feel about trees: Perceptions of ecosystem services and disservices associated with rural forests in southwestern France. Ecosyst Serv 42:101066. https://doi.org/10.1016/j.ecoser.2020.101066

Blanco J, Sourdril A, Deconchat M, et al (2019b) Social drivers of rural forest dynamics: A multi-scale approach combining ethnography, geomatic and mental model analysis. Landsc Urban Plan 188:132-142. https://doi.org/10.1016/j.landurbplan.2018.02.005

Boyd J, Banzhaf S (2007) What are ecosystem services? The need for standardized environmental accounting units. Ecol Econ 63:616-626. https://doi.org/10.1016/j.ecolecon.2007.01.002

Buijs A, Jacobs M (2021) Avoiding negativity bias: Towards a positive psychology of human-wildlife relationships. Ambio 50:281-288. https://doi.org/10.1007/s13280-020-01394-w

Buijs AE, Arts BJM, Elands BHM, Lengkeek J (2011) Beyond environmental frames: The social representation and cultural resonance of nature in conflicts over a Dutch woodland. Geoforum 42:329-341. https://doi.org/10.1016/j.geoforum.2010.12.008

Cáceres NC, Bornschein MR, Lopes WH, Percequillo AR (2007) Mammals of the Bodoquena Mountains, southwestern Brazil: an ecological and conservation analysis. Rev Bras Zool 24:426-435. https://doi.org/10.1590/S0101-81752007000200021

Campagne CS, Roche PK, Salles JM (2018) Looking into Pandora's Box: Ecosystem disservices assessment and correlations with ecosystem services. Ecosyst Serv 30:126-136. https://doi.org/10.1016/j.ecoser.2018.02.005

Chan KMA, Guerry AD, Balvanera P, et al (2012) Where are Cultural and Social in Ecosystem Services? A Framework for Constructive Engagement. BioScience 62:744-756. https://doi.org/10.1525/bio.2012.62.8.7

Costanza R, de Groot R, Braat L, et al (2017) Twenty years of ecosystem services: How far have we come and how far do we still need to go? Ecosyst Serv 28:1-16. https://doi.org/10.1016/j.ecoser.2017.09.008

de Wit MP, Crookes DJ, van Wilgen BW (2001) Conflicts of interest in environmental management : estimating. Biol Invasions 3:167-178. https://doi.org/10.1023/A:1014563702261

Díaz S, Pascual U, Stenseke M, et al (2018) Assessing nature’s contributions to people. Science 359:270-272. https://doi.org/10.1126/science.aap8826

Dunn RR (2010) Global Mapping of Ecosystem Disservices:The Unspoken Reality that Nature Sometimes Kills us. Biotropica 42:555-557. https://doi.org/10.1098/rspb.2010.0340.F

Escobedo FJ, Kroeger T, Wagner JE (2011) Urban forests and pollution mitigation: Analyzing ecosystem 
services and disservices. Environ Pollut 159:2078-2087. https://doi.org/10.1016/j.envpol.2011.01.010

Fischer A, Eastwood A (2016) Coproduction of ecosystem services as human-nature interactions-An analytical framework. Land Use Policy 52:41-50. https://doi.org/10.1016/j.landusepol.2015.12.004

Fisher B, Turner RK, Morling P (2009) Defining and classifying ecosystem services for decision making. Ecol Econ 68:643-653. https://doi.org/10.1016/j.ecolecon.2008.09.014

Franco JBS (2001) O Papel Da Embrapa Nas Transformações Do Cerrado. Caminhos Geogr 2:31-40

Friess D (2016) Ecosystem Services and Disservices of Mangrove Forests: Insights from Historical Colonial Observations. Forests 7:183. https://doi.org/10.3390/f7090183

Genin D, Aumeeruddy-Thomas Y, Balent G, Nasi R (2013) The Multiple Dimensions of Rural Forests: Lessons from a Comparative Analysis. Ecol Soc 18:art27. https://doi.org/10.5751/ES-05429-180127

Godoi MN, Laps RR, Ribeiro DB, et al (2018) Bird species richness, composition and abundance in pastures are affected by vegetation structure and distance from natural habitats: a single tree in pastures matters. Emu Austral Ornithol 118:201-211. https://doi.org/10.1080/01584197.2017.1398591

Haines-Young R, Potschin MB (2018) Common International Classification of Ecosystem Services (CICES) V5.1 and Guidance on the Application of the Revised Structure. 27

Harrington R, Anton C, Dawson TP, et al (2010) Ecosystem services and biodiversity conservation: concepts and a glossary. Biodivers Conserv 19:2773-2790. https://doi.org/10.1007/s10531-010-9834-9

Hodgson ID, Redpath SM, Sandström C, Biggs D (2020) The State of Knowledge and Practice on HumanWildlife Conflicts. Luc Hoffmann Institute, Gland, Switzerland

Huang J, Tichit M, Poulot M, et al (2015) Comparative review of multifunctionality and ecosystem services in sustainable agriculture. J Environ Manage 149:138-147. https://doi.org/10.1016/j.jenvman.2014.10.020

Kansky R, Knight AT (2014) Key factors driving attitudes towards large mammals in conflict with humans. Biol Conserv 179:93-105. https://doi.org/10.1016/j.biocon.2014.09.008

Koroiva R, Rodrigues ME, Valente-Neto F, Roque FO (2017) Odonates from bodoquena plateau: Checklist and information about endangered species. Biota Neotropica 17:. https://doi.org/10.1590/1676-0611-BN-2016-0310

Landers DH, Nahlik AM (2013) Final Ecosystem Goods and Services Classification System (FEGS-CS). 108. https://doi.org/EPA/600/R-13/ORD-004914

Lyytimäki J (2015) Ecosystem disservices: Embrace the catchword. Ecosyst Serv 12:136. https://doi.org/10.1016/j.ecoser.2014.11.008

Lyytimäki J, Sipilä M (2009) Hopping on one leg - The challenge of ecosystem disservices for urban green management. Urban For Urban Green 8:309-315. https://doi.org/10.1016/j.ufug.2009.09.003

Ma F, Eneji AE, Liu J (2015) Assessment of ecosystem services and dis-services of an agro-ecosystem based on extended emergy framework: A case study of Luancheng county, North China. Ecol Eng 82:241-251. https://doi.org/10.1016/j.ecoleng.2015.04.100

Machado F (2016) Brazil's new Forest Code: A guide for decision-makers in supply chains and governments. Brasilia, Brazil

Marchini S, Cavalcanti S, De Paula RC (2011) Predadores Silvestres e Animais Domésticos. Guia Prático de Convivência

McCauley DJ (2006) Selling out on nature. Nature 443:27-28. https://doi.org/10.1038/443027a

McElwee PD (2010) Resource Use Among Rural Agricultural Households Near Protected Areas in Vietnam: The Social Costs of Conservation and Implications for Enforcement. Environ Manage 45:113-131. https://doi.org/10.1007/s00267-009-9394-5

Methorst J, Arbieu U, Bonn A, et al (2020) Non-material contributions of wildlife to human well-being: a systematic review. Environ Res Lett 15:093005. https://doi.org/10.1088/1748-9326/ab9927

Myers N, Mittermeier RA, Mittermeier CG, et al (2000) Biodiversity hotspots for conservation priorities. Nature 403:853-858

Norgaard RB (2010) Ecosystem services: From eye-opening metaphor to complexity blinder. Ecol Econ 69:1219-1227. https://doi.org/10.1016/j.ecolecon.2009.11.009 
Norris CJ (2019) The negativity bias, revisited: Evidence from neuroscience measures and an individual differences approach. Soc Neurosci 1-15. https://doi.org/10.1080/17470919.2019.1696225

Nyhus PJ, Tilson R, Sumianto (2000) Crop-raiding elephants and conservation implications at Way Kambas National Park, Sumatra, Indonesia. Oryx 34:262-274. https://doi.org/10.1046/j.1365-3008.2000.00132.x

Palomo I, Felipe-Lucia MR, Bennett EM, et al (2016) Disentangling the Pathways and Effects of Ecosystem Service Co-Production, 1 st edn. Elsevier Ltd.

Pinto L, Ferreira CSS, Pereira P (2021) Environmental and socioeconomic factors influencing the use of urban green spaces in Coimbra (Portugal). Sci Total Environ 792:148293. https://doi.org/10.1016/j.scitotenv.2021.148293

Potschin MB, Haines-Young RH (2011) Ecosystem services: Exploring a geographical perspective. Prog Phys Geogr 35:575-594. https://doi.org/10.1177/0309133311423172

Potschin-Young M, Haines-Young R, Görg C, et al (2018) Understanding the role of conceptual frameworks: Reading the ecosystem service cascade. Ecosyst Serv 29:428-440. https://doi.org/10.1016/j.ecoser.2017.05.015

Power AG (2010) Ecosystem services and agriculture: tradeoffs and synergies. Philos Trans R Soc Lond B Biol Sci 365:2959-2971. https://doi.org/10.1098/rstb.2010.0143

QSR International Pty Ltd. (2021) NVivo (release 1.5)

R Core Team (2018) R: A Language and Environment for Statistical Computing.

Russell BH (2011) Research Methods in Anthropology: qualitative and quantitative approaches, Fifth edit. AltaMira Press, Lanham, Maryland

Saarikoski H, Jax K, Harrison PA, et al (2015) Exploring operational ecosystem service definitions: The case of boreal forests. Ecosyst Serv 14:144-157. https://doi.org/10.1016/j.ecoser.2015.03.006

Sabino J, Andrade LP de (2003) Uso e conservação da ictiofauna no ecoturismo da região de Bonito, Mato Grosso do Sul: o mito da sustentabilidade ecológica no Rio baía bonita (aquário natural de Bonito). Biota Neotropica 3:1-9. https://doi.org/10.1590/S1676-06032003000200002

Saunders ME (2020) Conceptual ambiguity hinders measurement and management of ecosystem disservices. J Appl Ecol 1365-2664.13665. https://doi.org/10.1111/1365-2664.13665

Schaubroeck T (2017) A need for equal consideration of ecosystem disservices and services when valuing nature; countering arguments against disservices. Ecosyst Serv 26:95-97. https://doi.org/10.1016/J.ECOSER.2017.06.009

Schröter M, van der Zanden EH, van Oudenhoven APE, et al (2014) Ecosystem Services as a Contested Concept: A Synthesis of Critique and Counter-Arguments. Conserv Lett 7:514-523. https://doi.org/10.1111/conl.12091

Shackleton CM, Ruwanza S, Sinasson Sanni GK, et al (2016) Unpacking Pandora's Box: Understanding and Categorising Ecosystem Disservices for Environmental Management and Human Wellbeing. Ecosystems 19:587-600. https://doi.org/10.1007/s10021-015-9952-z

Shapiro J, Báldi A (2014) Accurate accounting: How to balance ecosystem services and disservices. Ecosyst Serv 7:201-202. https://doi.org/10.1016/j.ecoser.2014.01.002

Simberloff D (2014) The "Balance of Nature"-Evolution of a Panchreston. PLoS Biol 12:e1001963. https://doi.org/10.1371/journal.pbio.1001963

Spangenberg JH, Görg C, Truong DT, et al (2014) Provision of ecosystem services is determined by human agency, not ecosystem functions. Four case studies. Int J Biodivers Sci Ecosyst Serv Manag 10:40-53. https://doi.org/10.1080/21513732.2014.884166

Star SL, Griesemer JR (1989) Institutional Ecology, 'Translations' and Boundary Objects: Amateurs and Professionals in Berkeley's Museum of Vertebrate Zoology, 1907-39. Soc Stud Sci 19:387-420. https://doi.org/10.1177/030631289019003001

Stokely TD, Betts MG (2020) Deer-mediated ecosystem service versus disservice depends on forest management intensity. J Appl Ecol 57:31-42. https://doi.org/10.1111/1365-2664.13532

Summers JK, Smith LM, Case JL, Linthurst RA (2012) A Review of the Elements of Human Well-Being with an Emphasis on the Contribution of Ecosystem Services. AMBIO 41:327-340. https://doi.org/10.1007/s13280- 


\section{2-0256-7}

Teixeira L, Tisovec-Dufner KC, Marin G de L, et al (2020) Linking human and ecological components to understand human-wildlife conflicts across landscapes and species. Conserv Biol 00:cobi.13537. https://doi.org/10.1111/cobi.13537

Vaz AS, Kueffer C, Kull CA, et al (2017) Integrating ecosystem services and disservices: insights from plant invasions. Ecosyst Serv 23:94-107. https://doi.org/10.1016/j.ecoser.2016.11.017

Vialatte A, Barnaud C, Blanco J, et al (2019) A conceptual framework for the governance of multiple ecosystem services in agricultural landscapes. Landsc Ecol 34:1653-1673. https://doi.org/10.1007/s10980-019-00829-4

Von Döhren P, Haase D (2015) Ecosystem disservices research: A review of the state of the art with a focus on cities. Ecol Indic 52:490-497. https://doi.org/10.1016/j.ecolind.2014.12.027

Zhang W, Ricketts TH, Kremen C, et al (2007) Ecosystem services and dis-services to agriculture. Ecol Econ 64:253-260. https://doi.org/10.1016/j.ecolecon.2007.02.024

Zhen H, Gao W, Yuan K, et al (2021) Internalizing externalities through net ecosystem service analysis-A case study of greenhouse vegetable farms in Beijing. Ecosyst Serv 50:101323.

https://doi.org/10.1016/j.ecoser.2021.101323 


\title{
Electronic Supplementary Material for
}

\begin{abstract}
A novel ecosystem (dis)service cascade model to navigate sustainability problems and its application in a changing agricultural landscape in Brazil
\end{abstract}

By Julien Blanco*, Beatriz Bellón, Liane Barthelemy, Baptiste Camus, Louise Jaffre, Anne-Sophie Masson, Alix Masure, Fabio de Oliveira Roque, Franco L. Souza, Pierre-Cyril Renaud

*Corresponding author: julien.blanco@ird.fr

This PDF file includes:

- Table S1

- Figures S1 and S2

- Interview guideline

- References 
Table S1: Overview of the main definitions of 'ecosystem services' and 'ecosystem disservices' concepts.

\begin{tabular}{llcl}
\hline Reference & Definition & Comments
\end{tabular}

Key definitions of 'Ecosystem Services'

(Costanza "Ecosystem goods (such as food) and services (such as et al. 1997) waste assimilation) represent the benefits human populations derive, directly or indirectly, from ecosystem functions. For simplicity, we will refer to ecosystem goods and services together as ecosystem services" (p.253)

(Daily "Ecosystem services are the conditions and processes 1997)

(de Groot et "we explicitly define ecosystem functions as "the al. 2002) capacity of natural processes and components to provide goods and services that satisfy human needs, directly or indirectly"” (p.394)

(MEA

(Boyd and Banzhaf 2007)

(Fisher et al. 2009)

"ecosystem services are the aspects of ecosystem utilized (actively or passively) to produce human wellbeing" (p.645)
ES are considered as the outcomes of ecosystem functions, which are "the habitat, biological or system properties or processes of ecosystems" (p.253).

The authors note that there is not necessarily a one-to-one correspondence between ES and ecosystem functions: a single ES can sometimes be the product of several functions, whereas a single function can contribute to several ES.

ES are also understood as 'joint products' as ecosystem functions and services are generally interdependent, which introduces a risk of 'double counting'.

ES are considered as ecological conditions and processes. They are distinct from ecosystem goods: they are the underlying conditions and processes to the production of ecosystem goods such as food and materials.

ES are considered as the outcome of ecosystem functions, the latter being the subset of ecosystem structure and processes from which humans derive benefits.

The authors write that "observed ecosystem functions are reconceptualised as 'ecosystem goods and services' when human values are implied' (p.395), which underlines their constructivist approach of the ES concept.

ES are broadly defined as benefits, and classified within four categories, i.e. supporting, provisioning, regulating and cultural ES.

ES are considered as end-products (and not intermediate products, which value is already embodied in the end-product); are different from benefits and from final consumed products; are components (and not ecological functions or processes, which are intermediate to the production of final ES).

This definition has been enforced for avoiding double-counting. ES strictly exclude all ecological functions that underlie their production, because these functions are already embodied in the value of the "final ecosystem service".

In this definition, services must be ecological phenomena and do not have to be directly utilized.

Defined this way, ecosystem services include ecosystem organization or structure as well as processes and/or functions if they are consumed or utilized by humanity (directly or indirectly). The functions or processes become services if there are humans that benefit from them. Without human beneficiaries they are not 'services', emphasizing ES as a social construct. 
(Harrington "Benefits that humans recognise as obtained from et al. 2010) ecosystems that support, directly or indirectly, their survival and quality of life"

(Potschin "a service is only a service if a human beneficiary can and Haines- be identified and that it is important to distinguish Young between the 'final services' that contribute to people's 2011) well-being and the 'intermediate ecosystem structures and functions' that give rise to them." (p.578).

(Costanza “"Ecosystem services' (ES) are the ecological

et al. 2017) characteristics, functions, or processes that directly or indirectly contribute to human wellbeing: that is, the benefits that people derive from functioning ecosystems" (p.3).

(Gunton et ES could be defined as "those ecological processes al. 2017) and their effects that certain humans appreciate" (p.250).

(Haines-

Young and

Potschin

2018)

Final ecosystem services "are defined as the contributions that ecosystems (i.e. living systems) make to human well-being. These services are final in that they are the outputs of ecosystems (whether natural, semi-natural or highly modified) that most directly affect the well-being of people" (p.3).

\section{Key definitions of 'Ecosystem Disservices'}

(Lyytimäki "we understand ecosystem disservices as functions of and Sipilä ecosystems that are perceived as negative for human 2009) well-being” (p.311)

(Agbenyega EDS are defined as "environmental 'bads' borne by et al. 2009) inaction) by another party" (p.552)
ES are defined as benefits and not as ecological attributes or processes.

This definition stresses the subjectivity of ES: ES do not exist per se (contrary to ecological processes and functions), but as subjective perceptions, socially situated and constructed.

ES are considered as the outcome of ecological functions and as entities from which humans derive benefits.

The authors highlight that it may not be needed to precisely define the boundaries between functions, services and benefits within the ES cascade. The fundamental task should rather be to "understand the mechanisms that link ecological systems to human well-being" (p.579)

In this definition, ecosystem services are "those [ecological] processes and functions that benefit people, consciously or un-consciously, directly or indirectly".

The authors note that thanks to the existence of appreciative ecologists, such a definition would have unlimited scope.

The paper also invites to avoid the language of ES and introduce an alternative 'Ecosystem Valuing Framework'.

This definition insists on the distinction between final ES (i.e. the services themselves) and intermediate ES (which encompass biophysical structures, processes and functions) in order to avoid double counting issues.

This definition emphasizes that EDS arise from the ecosystem, but are experienced differently by people according to various interpersonal and individual factors.

The authors also insist on the subjective dimension of ES and EDS, considering that "the same ecosystem function can be valued as a service or disservice depending on the parson making the valuation and the context" (L.311).

This definition insists on the role of humans in producing EDS: the actions of one party regarding the ecosystem might have negative consequences on another party.

The EDS identified in the study are not necessarily ecosystem functions (e.g. drug use, criminal activity) but are rather related to human actions. 
(Escobedo

et al. 2011)

(Huang et

al. 2015)

(Conway

and Yip

2016)

(Shackleton "Ecosystem disservices are the ecosystem generated

et al. 2016)

"Consistent with our definition of ecosystem services, ecosystem disservices are also defined as endproducts" (p.2081)

The authors use "the term "ecosystem disservices" to designate negative effects from ecosystem function such as pest damage and competition for water and sunlight from surrounding ecosystems" (p.143).

EDS are defined as "functions or end products of ecosystems that are perceived as negative for human well-being" (p.2)

functions, processes and attributes that result in perceived or actual negative impacts on human wellbeing" (p.590)
This definition is inspired by the ES definition proposed by (Boyd and Banzhaf 2007), so EDS are understood as end-products of the ecosystem.

The authors distinguish EDS from their associated costs, the latter being categorized into financial, social and environmental costs.

The authors insist on the necessity to distinguish 'disservices' which are primarily caused by human actions (such as pollution caused by agricultural activities), and 'ecosystem disservices' which are primarily caused by ecosystem functioning (such as pest damage to crops).

The authors highlight that through this definition, EDS can occur alongside ES and be experienced differently by different individuals or groups of individuals.

This seminal publication about EDS deeply elaborates the EDS concept and how it is distinct from ES and trade-offs between ES, as well as from human actions that have detrimental consequences. 


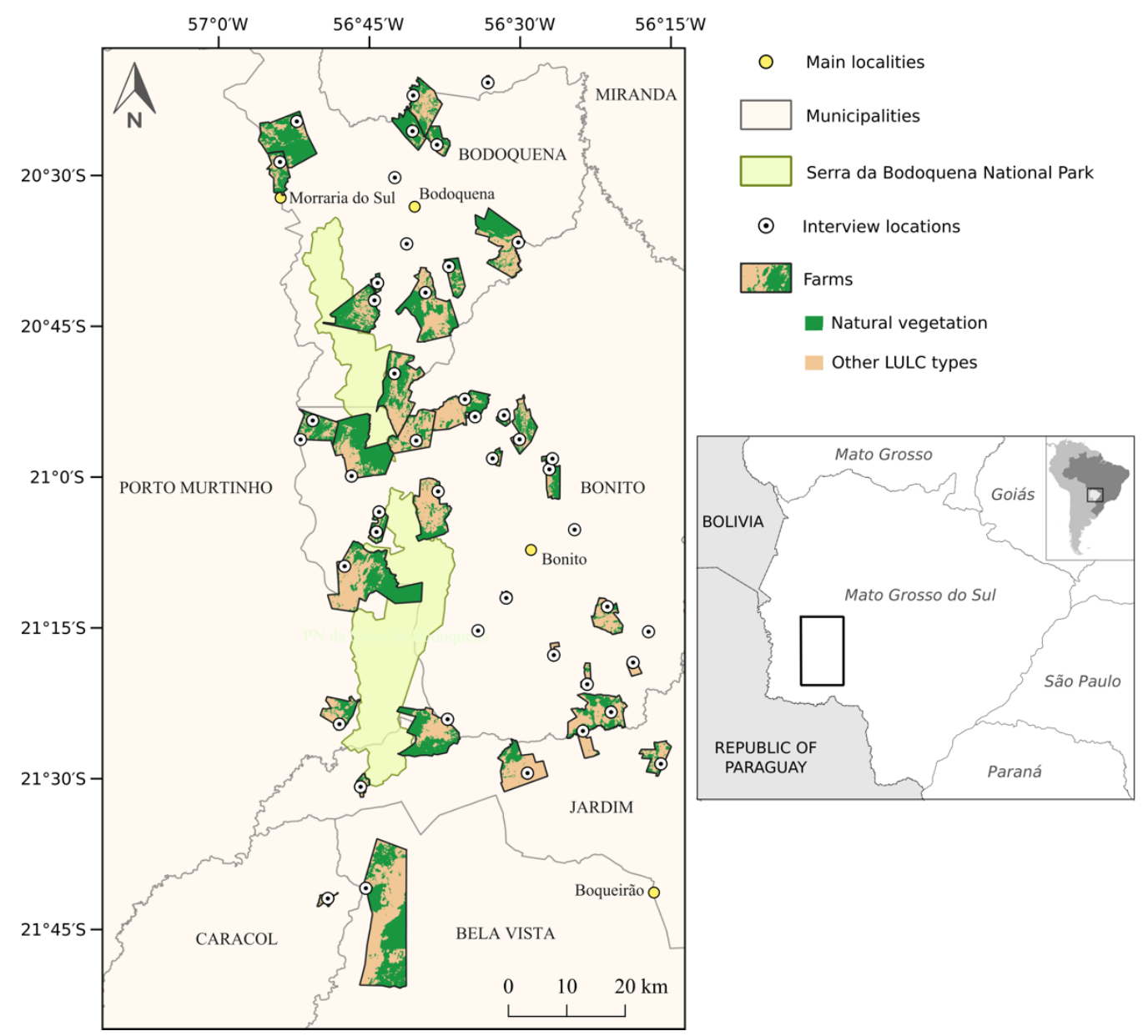

Figure S1: Location of the 45 farms investigated around the national park and the interview sites, plus the land cover (natural vegetation and other land use and land cover [LULC] types). 


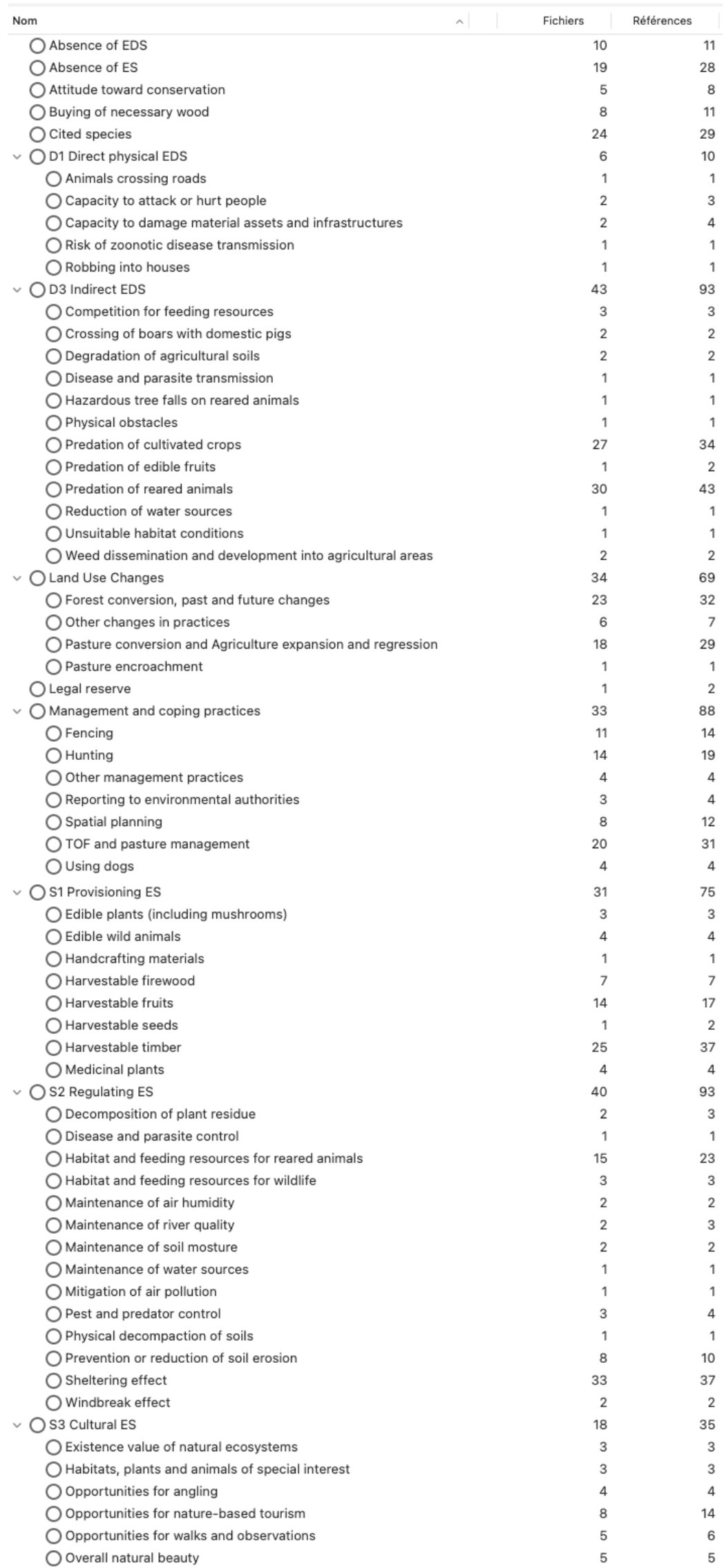

Figure S2: Screenshot of the NVivo coding scheme obtained as a result of the qualitative encoding (NVivo release 1.5). 


\section{S1. Interview guideline}

\begin{tabular}{lc}
\hline Code Id: & Identification \\
GPS coordinates: & Farm name: \\
Date of the interview: & Municipality: \\
Interviewers: & Place of the interview: \\
Comments: & \\
\hline
\end{tabular}

\section{Informant(s)}

Number of informants during the interview:

Role on the farm:

Age:

Gender:

Antiquity in the farm:

Professional career:

\section{FORESTS, TREES OUTSIDE FORESTS, AND LEGAL RESERVE}

The interview section to explore how farmers used and perceived rural forests was following a semistructured procedure, taking the form of an open-ended discussion with respondents. The interview was guided by the following inductive questions, and depending on their answers, respondents were asked to elaborate and to provide further details and explanations:

\section{About the services and disservices associated with forests in general:}

- Do you see any benefits with having forests on the farm?

- Do you, or people from the farm, make any use of the forests?

- Do you see any detriments with having forests on the farm?

- Do you see any problem with having forests on the farm?

\section{About the services and disservices associated with legal reserves in particular:}

- Is there any difference between the forests that are outside the legal reserve and the forests that are inside the legal reserve with regards to their benefits and uses, and to their detrimental and problematic aspects?

\section{About the services and disservices associated with trees outside forests:}

- Regarding the trees and groves that are outside forests (that are in pasture and cropped areas for example), do you see any benefits of having them? Do you use them in any way?

- Regarding the trees and groves that are outside forests (that are in pasture and cropped areas for example), do you see any detriments of having them? Do they pose any problem? 


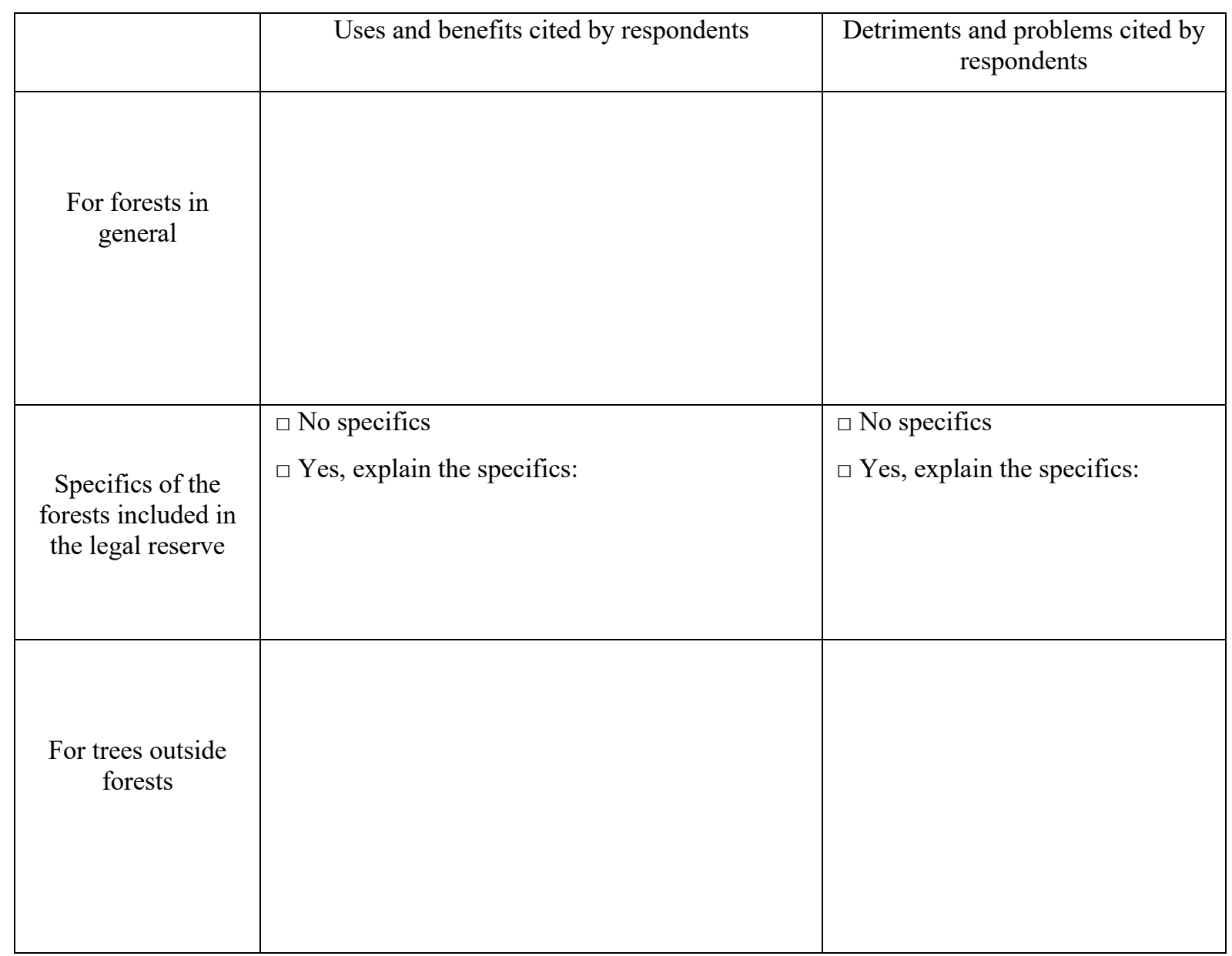




\section{References}

Agbenyega O, Burgess PJ, Cook M, Morris J (2009) Application of an ecosystem function framework to perceptions of community woodlands. Land Use Policy 26:551-557.

https://doi.org/10.1016/j.landusepol.2008.08.011

Boyd J, Banzhaf S (2007) What are ecosystem services? The need for standardized environmental accounting units. Ecol Econ 63:616-626. https://doi.org/10.1016/j.ecolecon.2007.01.002

Conway TM, Yip V (2016) Assessing residents' reactions to urban forest disservices: A case study of a major storm event. Landsc Urban Plan 153:1-10. https://doi.org/10.1016/j.landurbplan.2016.04.016

Costanza R, D'Arge R, de Groot R, et al (1997) The value of the world's ecosystem services and natural capital. Nature 387:253-260. https://doi.org/10.1038/387253a0

Costanza R, de Groot R, Braat L, et al (2017) Twenty years of ecosystem services: How far have we come and how far do we still need to go? Ecosyst Serv 28:1-16. https://doi.org/10.1016/j.ecoser.2017.09.008

Daily GC (1997) Introduction: What are ecosystem services? In: Daily GC (ed) Nature's Services: Societal Dependence On Natural Ecosystems. Island Press, Washington, DC, p 412

de Groot RS, Wilson M a, Boumans RMJ (2002) A typology for the classification, description and valuation of ecosystem functions, goods and services. Ecol Econ 41:393-408. https://doi.org/10.1016/S0921-8009(02)00089-7

Escobedo FJ, Kroeger T, Wagner JE (2011) Urban forests and pollution mitigation: Analyzing ecosystem services and disservices. Environ Pollut 159:2078-2087. https://doi.org/10.1016/j.envpol.2011.01.010

Fisher B, Turner RK, Morling P (2009) Defining and classifying ecosystem services for decision making. Ecol Econ 68:643-653. https://doi.org/10.1016/j.ecolecon.2008.09.014

Gunton RM, van Asperen EN, Basden A, et al (2017) Beyond Ecosystem Services: Valuing the Invaluable. Trends Ecol Evol 32:249-257. https://doi.org/10.1016/j.tree.2017.01.002

Haines-Young R, Potschin MB (2018) Common International Classification of Ecosystem Services (CICES) V5.1 and Guidance on the Application of the Revised Structure. 27

Harrington R, Anton C, Dawson TP, et al (2010) Ecosystem services and biodiversity conservation: concepts and a glossary. Biodivers Conserv 19:2773-2790. https://doi.org/10.1007/s10531010-9834-9

Huang J, Tichit M, Poulot M, et al (2015) Comparative review of multifunctionality and ecosystem services in sustainable agriculture. J Environ Manage 149:138-147. https://doi.org/10.1016/j.jenvman.2014.10.020

Lyytimäki J, Sipilä M (2009) Hopping on one leg - The challenge of ecosystem disservices for urban green management. Urban For Urban Green 8:309-315. https://doi.org/10.1016/j.ufug.2009.09.003

MEA (2005) Ecosystems and Human Well-being: Synthesis. Island Press, Washington, DC

Potschin MB, Haines-Young RH (2011) Ecosystem services: Exploring a geographical perspective. Prog Phys Geogr 35:575-594. https://doi.org/10.1177/0309133311423172

Shackleton CM, Ruwanza S, Sinasson Sanni GK, et al (2016) Unpacking Pandora's Box: Understanding and Categorising Ecosystem Disservices for Environmental Management and Human Wellbeing. Ecosystems 19:587-600. https://doi.org/10.1007/s10021-015-9952-z 